\title{
AVALIAÇÃO DE CARACTERÍSTICAS VISUAIS E MECÂNICAS DE ELETRODOS E6013 E E7018, SOLDADOS EM AÇO ASTM A36, COM DIFERENTES CONDIÇÕES DE ARMAZENAMENTO
}

\author{
EVALUATION OF VISUAL AND MECHANICAL CHARACTERISTICS OF \\ ELECTRODES E6013 AND E7018, WELDED IN ASTM A36 STEEL, WITH \\ DIFFERENT STORAGE CONDITIONS
}

\author{
Alessandro Fraga Farah ${ }^{\mathrm{I}}$ \\ Daniel de Almeida Santos ${ }^{\text {II }}$ \\ Solange Pereira dos Santos Farah ${ }^{\mathrm{III}}$ \\ Ariel Carlos de Macedo ${ }^{\mathrm{IV}}$ \\ Marcia Aparecida Gomes ${ }^{V}$
}

\begin{abstract}
RESUMO
Os consumíveis de soldagem têm um papel fundamental na união de peças, onde os processos de soldagem apresentam bons índices de produtividade, os eletrodos revestidos estão presentes em soldagens de grande responsabilidade. Isso se deve às ótimas características do metal de solda depositado por esse tipo de processo. Entretanto, um dos problemas que pode prejudicar a sua eficiência é a alta predisposição a absorção de umidade. Com base neste aspecto, esse trabalho tem o objetivo de avaliar a importância do armazenamento do eletrodo revestido. Foram avaliadas propriedades metalúrgicas e mecânicas de depósitos de solda com os Eletrodos E6013 e E7018, quando submetidos às normas de armazenamento e comparadas com uma situação adversa à solicitação dos fabricantes, que visam garantir a qualidade mínima do consumível para aplicação em soldagem, contribuindo com a segurança e saúde dos usuários desse processo, além de permitir sua total utilidade. As soldagens foram realizadas sobre um aço ASTM A36 com juntas em V. Após a soldagem foram confeccionados corpos de prova para os ensaios de líquido penetrante (LP), metalografia e dureza. O ensaio de LP mostrou pouca diferença nas condições ensaiadas. Os resultados de metalografia mostraram pequenas diferenças na microestrutura das zonas fundidas (ZF), sem variação significativa na zona termicamente afetada (ZTA), e os resultados de dureza, tanto na ZTA quanto na ZF, não apresentaram variações significativas.
\end{abstract}

Palavras-chave: Soldagem com Eletrodo revestido. Armazenamento de eletrodos. Eletrodo E6013. Eletrodo E7018.

\footnotetext{
${ }^{\text {I }}$ Prof. Pós-Dr. da Faculdade de Tecnologia Deputado Waldyr Alceu Trigo de Sertãozinho (Fatec-Stz) - São Paulo - Brasil. E-mail: alessandro.farah@fatec.sp.gov.br

II Engenheiro de Produção e Estudante do curso superior de Tecnologia em Mecânica: processos de soldagem da Faculdade de Tecnologia Deputado Waldyr Alceu Trigo de Sertãozinho (Fatec-Stz) - São Paulo - Brasil. Email: eng.daniel.almeida@gmail.com

III Prof. Ms. da Faculdade de Tecnologia Deputado Waldyr Alceu Trigo de Sertãozinho (Fatec-Stz) - São Paulo Brasil. E-mail: solangepfarah@gmail.com

IV Auxiliar Docente e Tecnólogo em Mecânica: processos de soldagem - Faculdade de Tecnologia Deputado Waldyr Alceu Trigo de Sertãozinho (Fatec-Stz) - São Paulo - Brasil. E-mail: ariel.macedo2@fatec.sp.gov.br

v Auxiliar Docente e Ms. da Faculdade de Tecnologia Deputado Waldyr Alceu Trigo de Sertãozinho (Fatec-Stz) São Paulo - Brasil. E-mail: marcia.gomes@fatec.sp.gov.br
} 


\begin{abstract}
Welding consumables play a key role in joining parts, where welding processes have good productivity rates, the coated electrodes are present in the high responsible welding. This is due to the excellent characteristics of the weld metal deposited by this type of process. However, one of the problems that can harm its efficiency is its high predisposition to humidity absorption. Based on this aspect, this work aims to assess the importance of storing the coated electrode. Metallurgical and mechanical properties of weld deposits were evaluated with Electrodes E6013 and E7018, when subjected to storage standards and compared with an adverse situation at the request of manufacturers, which aim to ensure the minimum quality of the consumable for application in welding, contributing to the safety and health of users of this process, in addition to allowing its full utility. The welds were carried out on an ASTM A36 steel with $\mathrm{V}$ joints. After the welding, test bodies were made for the liquid penetrant (LP), metallography and hardness tests. The LP test showed little difference under the conditions tested. The metallography results showed small differences in the microstructure of the weld metal zones (WM), without significant variation in the heat affected zone (HAZ), and the hardness results, both in the HAZ and in the WM, did not show significant variations.
\end{abstract}

Keywords: Shielded Metal Arc Welding. Storage of electrodes. E6013 electrode. E7018 electrode.

Data de submissão do artigo: 25/06/2021.

Data de aprovação do artigo: 31/08/2021.

DOI: $10.33635 /$ sitefa.v4i1.172

\title{
1 INTRODUÇÃO
}

A soldagem é o mais importante processo de união de metais utilizados industrialmente. A possibilidade de unir materiais de ligas metálicas permitiu grandes avanços tecnológicos, e contribuiu principalmente para a evolução dos processos metalúrgicos.

A soldagem é muito versátil em termos dos tipos de ligas metálicas e das espessuras que podem ser unidas, isso devido aos inúmeros processos de soldagem disponíveis. Pode-se soldar peças de diferentes espessuras, desde componentes eletrônicos até equipamento de grandes dimensões como navios, aviões, vasos de pressão etc. (MARQUES et al., 2005).

Dentre os vários processos de soldagem disponíveis, há alguns que não necessitam de materiais de adição e aqueles que utilizam algum tipo de metal de adição como parte do processo que é comumente conhecido como insumos ou consumíveis de soldagem. De acordo com Wainer et al., (2005), esse metal de adição é responsável pela união da maioria das ligas metálicas e equipamentos fabricados pela indústria, e pode-se contar com inúmeros tipos de consumíveis para diversos tipos de ligas.

O processo de soldagem com eletrodo revestido é o mais amplamente utilizado. Possui a maior flexibilidade entre todos os processos de soldagem uma vez que a maioria dos metais pode ser unida ou revestida pela soldagem. Existe uma grande variedade de eletrodos revestidos, facilmente encontrados no mercado, cada eletrodo contendo no seu revestimento a capacidade de produzir os próprios gases de proteção dispensando o suprimento adicional de gases necessários em outros processos de soldagem. Entretanto, a capacidade de absorver umidade de seu revestimento obriga o usuário a cumprir procedimentos de armazenagem e manuseio visando manter em um nível seguro o teor de hidrogênio difusível no metal de solda.

Simpósio de Tecnologia (Sitefa) - Fatec Sertãozinho - SP, v. 4, n. 1, p. 54-65, 2021. ISSN 2675-7540 
O objetivo deste trabalho foi analisar as características visuais, microestruturais e mecânicas da zona fundida e zona termicamente afetada, através de ensaios de metalografia e dureza, com o intuito de verificar a influência da condição de armazenamento de eletrodos revestidos de baixo teor de carbono.

\section{PROCESSO DE SOLDAGEM POR ELETRODO REVESTIDO}

A soldagem com eletrodo revestido é definida como um processo de soldagem com arco elétrico, onde a união é produzida pelo calor do arco criado entre um eletrodo revestido e a peça a soldar (WAINER et al. 2005). A Figura 1 apresenta um desenho esquemático da soldagem com eletrodo revestido.

Figura 1 - Desenho esquemático de uma soldagem com eletrodo revestido

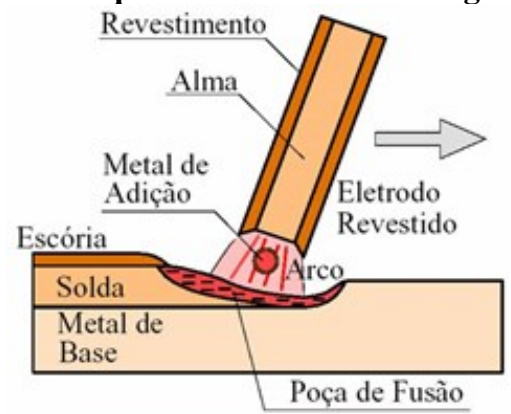

Fonte: ESAB, 2021

Segundo Marques et al. (2005), o eletrodo revestido é composto por uma vareta metálica, conhecida como "alma", que conduz a corrente elétrica e fornece o metal de adição para preenchimento da junta. A alma é coberta por uma mistura de diferentes materiais que forma uma camada de revestimento do eletrodo que possui várias funções na solda, como: estabilizar o arco elétrico; ajustar a composição química da solda; proteger a poça de fusão e o metal de solda contra contaminação pela atmosfera, através da geração de gases e de uma camada de escória; conferir características operacionais, mecânicas/metalurgicas ao eletrodo e à solda (SANTOS et al. 2014; LIMA II. e BRACARENSE, 2007; MARQUES; et al., 2005).

\subsection{Equipamentos}

De acordo com Wainer et al., (2005), o equipamento básico para realização de uma soldagem manual com eletrodo revestido, possui uma das mais simples configurações se comparado a outros processos de soldagem a arco elétrico, sendo: fonte de energia; alicate para fixação dos eletrodos; cabos de interligação; pinça para ligação à peça; equipamento para proteção individual (EPI); equipamentos para limpeza da solda.

A Figura 2 a seguir, mostra de forma ilustrativa os equipamentos necessários para realização da soldagem a arco com eletrodo revestido. 
Figura 2 - Equipamentos para soldagem a arco com eletrodo revestido

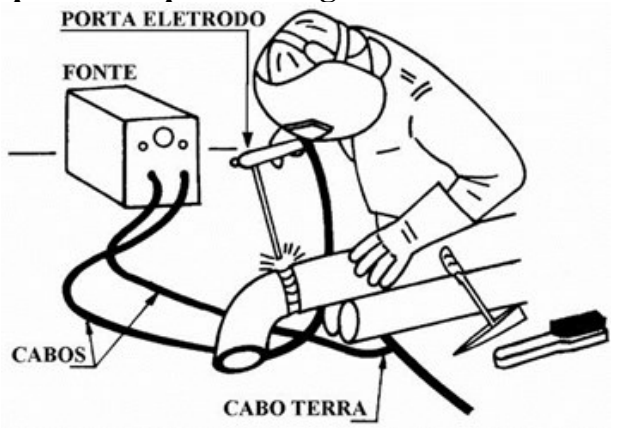

Fonte: MARQUES et al., 2005, p.183

\subsection{Consumíveis}

O consumível para o processo de soldagem em eletrodo revestido é constituído por uma vareta metálica, conhecida como alma, revestida por uma camada de fluxo. A composição do revestimento determina as características operacionais do eletrodo, e pode influenciar na composição e nas propriedades mecânicas da solda efetuada. (MARQUES; et al., 2005).

Segundo Guedes (2009), Wainer et al., (2005) e Marques et al. (2005), além das funções já citadas, o revestimento serve ainda para realizar ou possibilitar reações de refino metalúrgico, como desoxidação e dessulfuração, formar a camada de escória protetora e facilitar sua remoção, facilitar a soldagem nas diversas posições, reduzir o nível de respingos e fumos, diminuir a velocidade de resfriamento da solda, possibilitar o uso de diferentes tipos de corrente e polaridade, aumentar a taxa de deposição, entre outras.

\subsection{Armazenagem dos eletrodos}

A armazenagem dos eletrodos revestidos não possui uma norma oficial. Entretanto, os fabricantes, associações e pesquisadores, disponibilizam informações e condições de armazenamento e acondicionamento para manter suas propriedades preservadas.

De acordo com Wainer et al., (2005), na armazenagem dos eletrodos revestidos, devem ser tomadas certas precauções, principalmente os eletrodos básicos de baixo teor de hidrogênio, que são muito higroscópicos e necessitam de cuidados especiais para que suas características não sejam afetadas. Segundo Infosolda (2021), um eletrodo úmido poderá causar inúmeros defeitos na solda: porosidade no início ou em todo o cordão de solda, trincas ao lado e sob o cordão, arco instável, respingos abundantes e acabamento ruim.

ESAB (2021), sugere que após a abertura das latas que contém os eletrodos, os mesmos deverão ser colocados numa estufa apropriada e o local de armazenagem dos eletrodos em suas embalagens originais deverá ser adequadamente preparado para permitir a manutenção das suas propriedades. Dois aspectos deverão ser considerados e bem controlados: a temperatura e a umidade relativa do ar (EUTETIC, 2021).

\subsection{Ensaios}

Tendo em vista os tipos de ensaios disponíveis, a escolha adotada nesse estudo, levará em conta o aspecto visual, a microestrutura e a dureza das amostras soldadas, a fim de, identificar possíveis variações que possam ocorrer. Sendo assim, foram escolhidos os ensaios visuais (EV), de líquido penetrante (LP), de dureza e metalográfico. 


\subsubsection{Ensaio Visual}

Segundo Garcia et al., (1999), o ensaio visual é um dos ensaios não destrutivos mais utilizados, que consiste na observação visual da peça. Detecta-se a olho nu, uma imperfeição ou uma falha do processo. Nesse tipo de ensaio, deve-se levar em conta que a experiência do operador ou inspetor exerce grande influência nos resultados.

\subsubsection{Ensaio de Líquido Penetrante (LP)}

De acordo com Garcia et al., (1999), o ensaio de líquido penetrante, faz parte dos ensaios não destrutivos e baseia-se na penetração de líquidos em trincas e rachaduras superficiais de peças por ação do fenômeno da capilaridade, e é aplicado, portanto na verificação da existência de trincas superficiais de difícil observação a olho nu.

\subsubsection{Ensaio de Dureza}

O ensaio de dureza consiste na impressão de uma pequena marca feita na superfície da peça. Essa marca é feita por pressão com uma ponta de penetração, e a medida da dureza do material ou dureza superficial é dada em função das características da marca de impressão e da carga aplicada (GARCIA, et al., 1999).

\subsubsection{Ensaio de Metalografia}

O ensaio de metalográfico originou-se do fato que as propriedades mecânicas de um material metálico não dependem somente de sua composição química, mas também da sua microestrutura. A metalografia estuda os materiais, com o auxílio do microscópio ótico, visando à identificação dos seus microconstituintes. Este estudo é feito em superfícies previamente polidas e, em geral, atacadas por um reativo adequado (COLPAERT, 2008).

\section{PROCEDIMENTOS METODOLÓGICOS}

Foram elaboradas 8 chapas de aço ASTM A36 com as seguintes dimensões: $100 \mathrm{~mm} \mathrm{x}$ $50 \mathrm{~mm} \times 10 \mathrm{~mm}$. As chapas foram chanfradas em "V" com ângulo de $45^{\circ}$, e ponteadas para o início da soldagem. A Figura 3 mostra a preparação dos corpos de prova para realização dos ensaios.

Figura 3 - Preparação corpos de prova

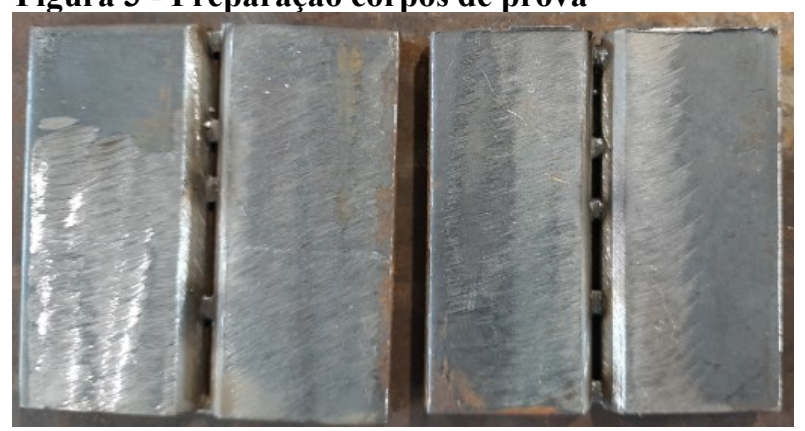

Fonte: Arquivo pessoal dos autores (2021)

\subsection{Processo de Soldagem}

As soldas dos corpos de prova foram realizadas utilizando-se de uma máquina retificadora de solda com eletrodo revestidos modelo: LINCOLN POWERWAVE S350-CE. A soldagem foi realizada com quatro corpos de prova, onde dois foram unidos com eletrodo 
E6013, um com todas as recomendações do fabricante no que se diz respeito à aplicação, armazenamento e conservação do consumível, e o outro com o consumível num ambiente sujeito a umidade e poeira, contrário ao que o fabricante recomenda. Os outros dois foram soldados com o eletrodo E7018, utilizando o mesmo procedimento.

A Tabela 1 resume o procedimento utilizado nas amostras de soldagem.

Tabela 1 - Denominação da amostra e sua condição de soldagem

\begin{tabular}{c|c|c|c|c}
\hline Amostra & Condição de Armazenamento & Tensão (V) & Amperagem (A) & Diâmetro (mm) \\
\hline E6013-I & Estufa & 23 & 70 & 3,25 \\
\hline E6013-II & Externo & 27 & 85 & 3,25 \\
\hline E7018-I & Estufa & 23 & 100 & 3,25 \\
\hline E7018-II & Externo & 25 & 100 & 3,25 \\
\hline
\end{tabular}

Fonte: Arquivo pessoal dos autores (2021)

\subsection{Ensaio de Líquido Penetrante (LP)}

O ensaio de LP foi executado com penetrante visível lavável em água (SKL-WP da Magnaflux) e revelador à base de solvente, não aquoso (SKD-S2 da Magnaflux), seguindo as recomendações do fabricante.

\subsection{Ensaio Metalográfico}

As amostras foram cortadas, embutidas em baquelite, lixadas na sequência de lixas de 150 a $600 \#$, polidas com alumina de 0,1 e $0,05 \mu \mathrm{m}$, atacadas quimicamente com Nital $3 \%$, observadas no microscópio ótico e registradas por fotografia.

\subsection{Ensaio de Dureza}

A análise da dureza foi feita com durômetro Vickers com carga de 9,8N. As medições foram realizadas nas amostras, após a metalografia, e numa sequência de medições que inicia no metal base (MB), passa pela ZTA, ZF, ZTA e finaliza no MB.

\section{RESULTADOS E DISCUSSÃO}

As amostras analisadas visualmente estão a seguir. As Figuras 4 (a), (b), (c) e (d) mostram os corpos de prova das amostras E6013-I, E6013-II, E7018-I e E7018-II respectivamente.

Figura 4 - Corpos de prova soldados. (a) E6013-I; (b) E6013-II;

(c) E7018-I; (d) E7018-II

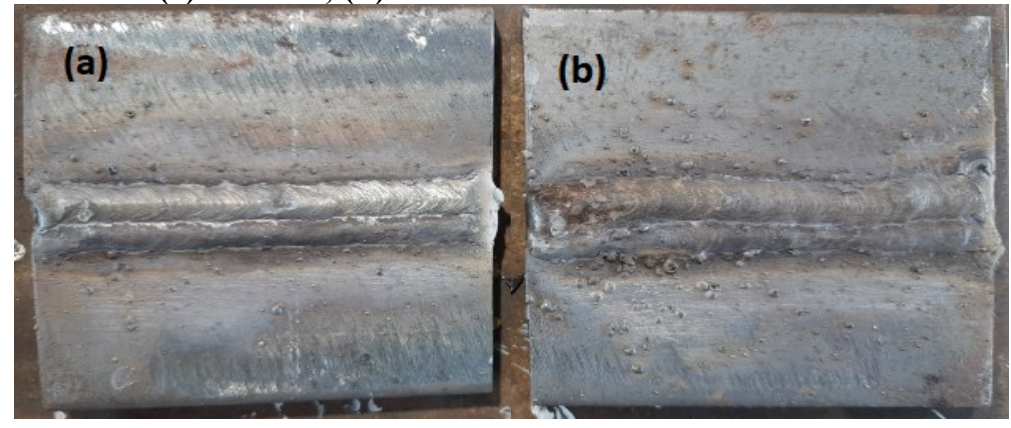




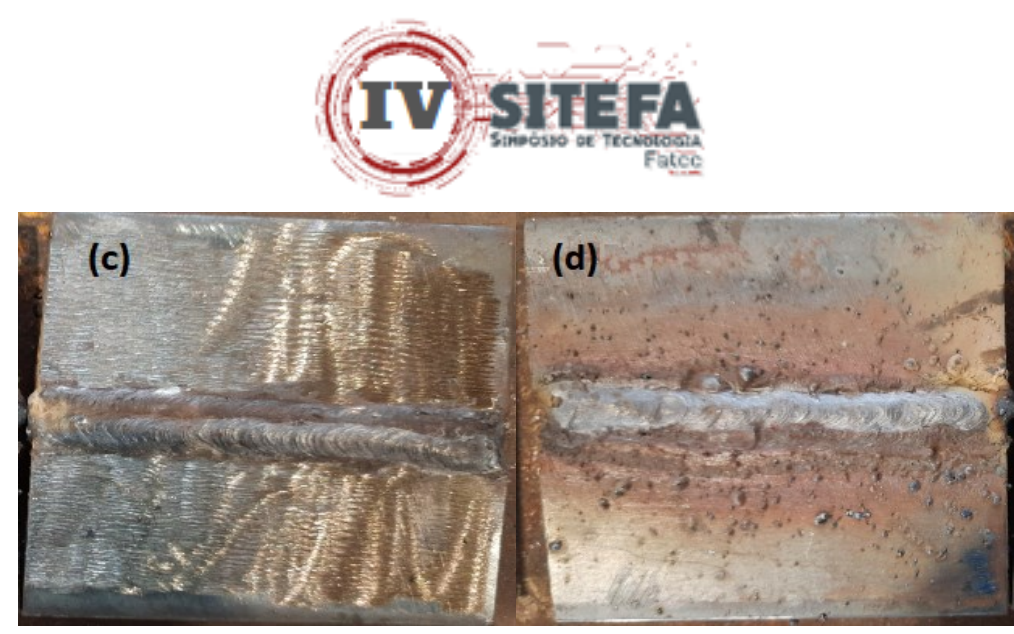

Fonte: Arquivo pessoal dos autores (2021)

Pode-se observar na figura 4 algumas diferenças, devido ao armazenamento do eletrodo utilizado em cada amostra. Nota-se uma maior quantidade de respingos de soldagem nos corpos de prova onde o consumível foi mal acondicionado (E6013-II e E7018-II), além do espalhamento do cordão de solda, rechupe de cratera, má sobreposição do cordão de solda, deposição insuficiente e pontos de mordedura.

\subsection{Teste de líquido penetrante}

Os resultados do ensaio de LP estão nas figuras a seguir. As Figuras 5 (a), (b), (c) e (d) mostram as amostras E6013-I, E6013-II, E7018-I e E7018-II, respectivamente.

O ensaio de LP não apresentou nenhuma trinca nas amostras soldadas, tanto com o eletrodo E6013 quanto com o eletrodo E7018. As figuras mostram que os eletrodos quando armazenados de forma inadequada, tendem a apresentar pouco ou nenhum defeito superficial, além dos já citados na análise visual, se comparado aos eletrodos com armazenagem correta.

Figura 5 - Ensaio de LP nas amostras soldadas. (a) E6013-I; (b) E6013-II; (c) E7018-I; (d) E7018-II

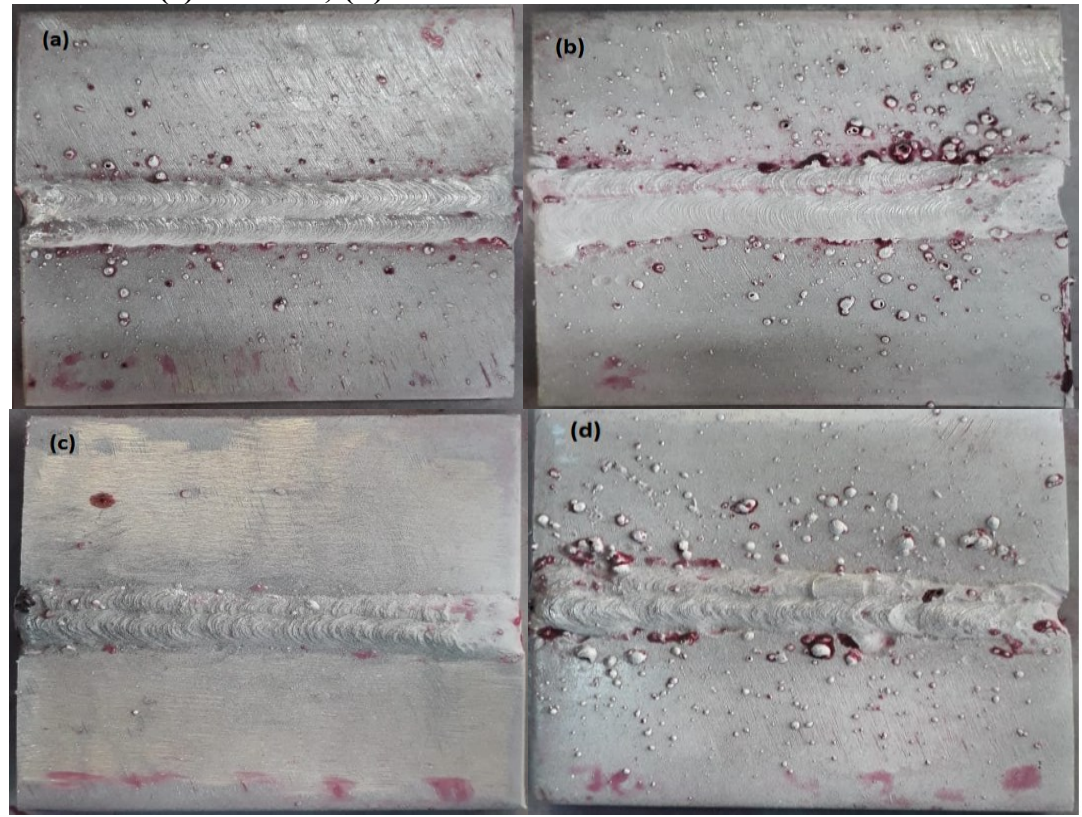

Fonte: Arquivo pessoal dos autores (2021) 


\subsection{Ensaio de dureza}

Os resultados das medições foram plotados em gráficos, para que se possa identificar as variações de dureza nos principais pontos de análise. Sendo assim, os resultados obtidos no ensaio de dureza Vickers, estão dispostos no Gráfico 1.

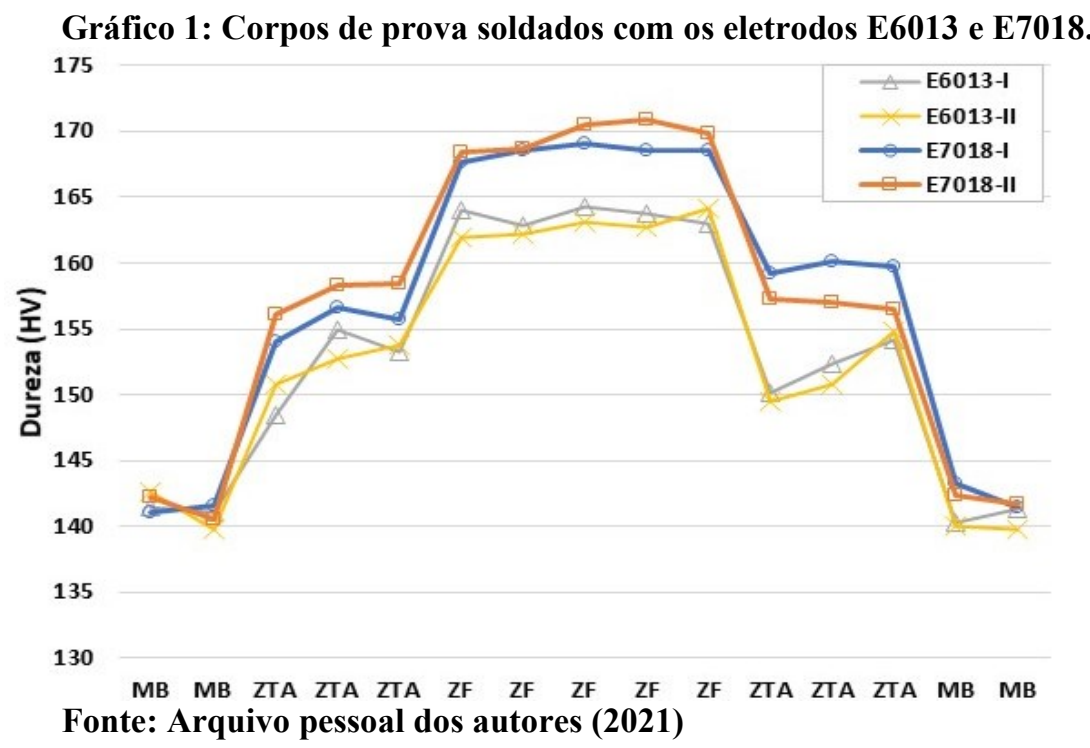

O Gráfico 1 mostra as variações da dureza entre o MB, a ZTA e ZF, onde essas variações são normais nesse tipo de soldagem, onde o MB tem uma dureza menor que a ZTA e essa menor que a ZF (IRIKURA, 2006).

O aumento de dureza na ZTA é devido ao refino dos grãos e o aumento de dureza na ZF é devido à morfologia da ferrita (ALVES, 2016; MOTOYAMA, 2007; IRIKURA, 2006). Nota-se que também não houve variação significativa da dureza entre as amostras E6013-I e E6013-II. Além das variações entre MB, ZTA e ZF, nas amostras soldadas com o eletrodo E7018, também não se percebeu mudança significativa entre as amostras E7018-I e E7018-II nas durezas das regiões analisadas, conforme mostra o Gráfico 1.

\subsection{Metalografia}

Os resultados dos ensaios metalográficos são mostrados a seguir.

As Figuras 6 (a), (b), (c) e (d) a seguir, mostram a microestrutura do metal de base e a ZTA das amostras E6013-I, E6013-II, E7018-I e E7018-II, respectivamente. A região da ZTA é caracterizada pela presença de grãos refinados de ferrita e perlita (ALVES, 2016).

Nota-se nas Figuras 6 (a) e (b) a diferença de tamanho de grãos entre o MB e a ZTA, entretanto não há variação microestrutural significativa entre as amostras E6013-I e E6013-II. As Figuras 6 (c) e (d) mostram que o tamanho de grãos entre o MB e a ZTA, também não variaram significativamente entre as amostras E7018-I e E7018-II.

A microestrutura nas quatro situações é composta de ferrita e perlita. 


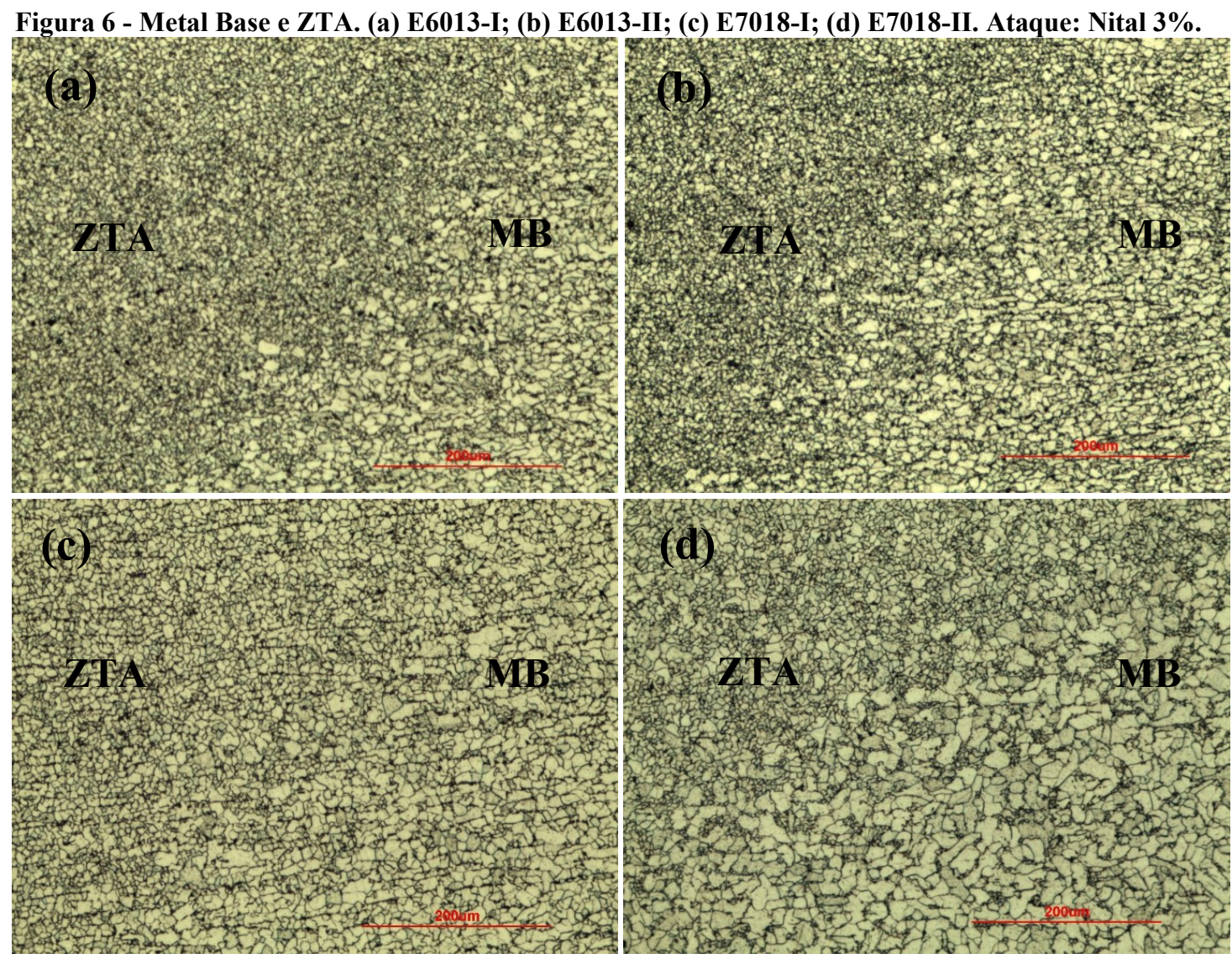

Fonte: Arquivo pessoal dos autores (2021)

A seguir, as Figuras 7 (a), (b), (c) e (d) mostram a microestrutura da ZTA e a Zona Fundida, das amostras E6013-I, E6013-II, E7018-I e E7018-II, respectivamente. Nota-se a presença de grãos colunares na ZF, para todas as microestruturas. Nas Zonas Termicamente Afetadas, bem próximas às Zonas Fundidas, é possível verificar a mudança microestrutural ocorrida pelo aumento da temperatura, que torna essa região de granulação grosseira com placas de ferrita, decorrentes da decomposição da austenita.

As microestruturas formadas nessa região apresentaram Ferrita Primária - $(\mathrm{PF})$, Ferrita de Segunda Fase Alinhada - FS(A), Ferrita de Segunda Fase Não Alinhada - FS(NA) e Agregados de Ferrita Carboneto/Perlita - FC(P), que corrobora com os trabalhos de Alves (2016), Lima Júnior (2013), Guedes (2009) e Irikura (2006). 


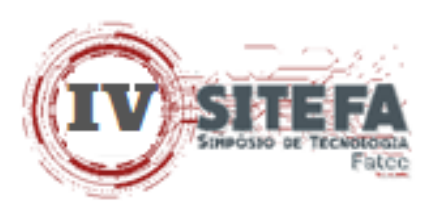

Figura 7 - ZF e ZTA. (a) E6013-I; (b) E6013-II; (c) E7018-I; (d) E7018-II; Ataque: Nital 3\%.
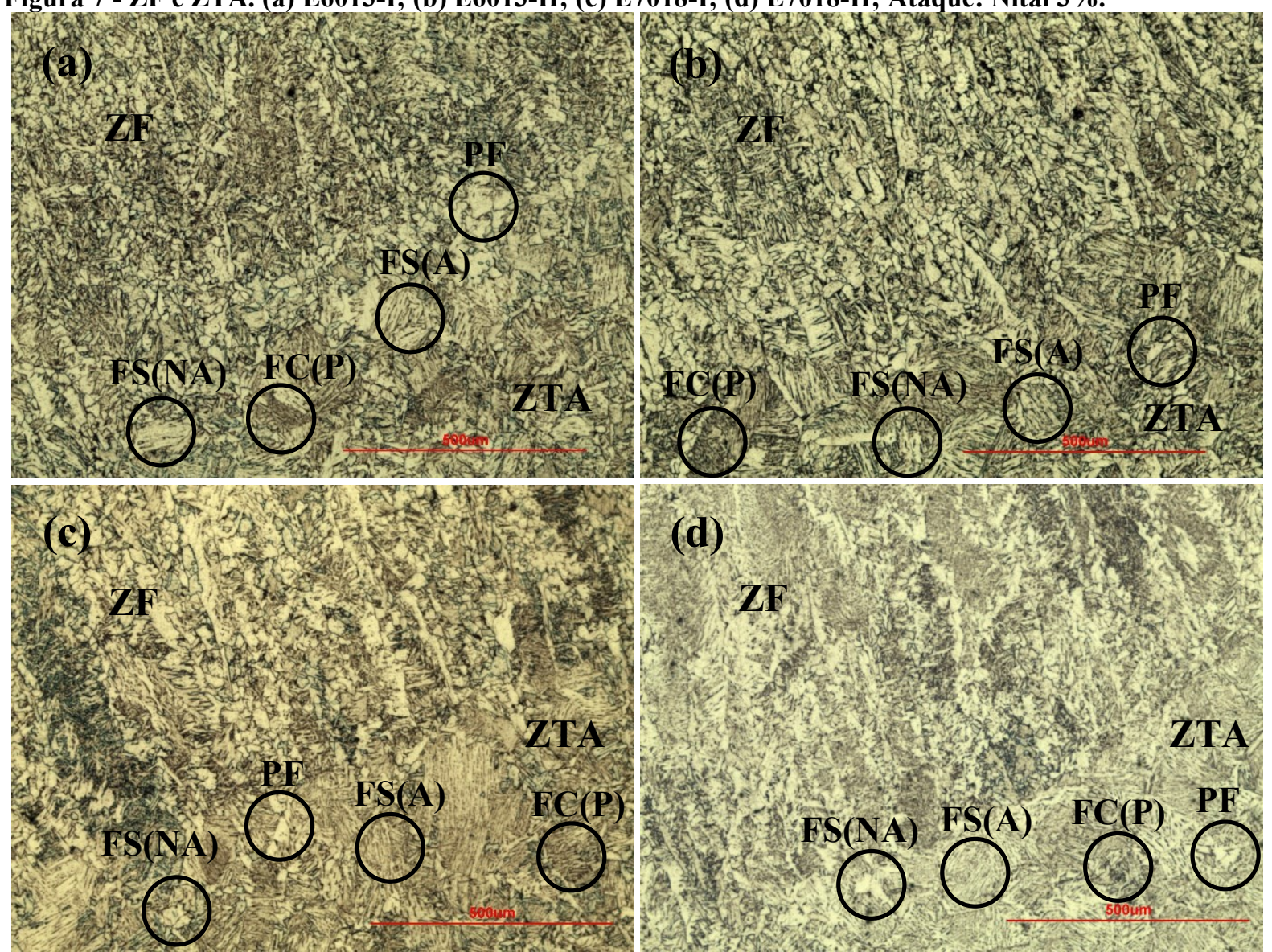

Fonte: Arquivo pessoal dos autores (2021)

As microestruturas formadas na ZF serão mostradas a seguir com maior resolução, para uma melhor identificação das fases presentes.

A seguir, as Figuras 8 (a), (b), (c) e (d) mostram a microestrutura da Zona Fundida.

As microestruturas formadas nessa região apresentaram Ferrita Primária - $(\mathrm{PF})$, Ferrita de Segunda Fase Alinhada - FS(A), Ferrita de Segunda Fase Não Alinhada - FS(NA) e Agregados de Ferrita Carboneto/Perlita - FC(P) e Ferrita Acicular - AF. 
Figura 8 - ZF. (a) E6013-I; (b) E6013-II; (c) E7018-I; (d) E7018-II Ataque: Nital 3\%.

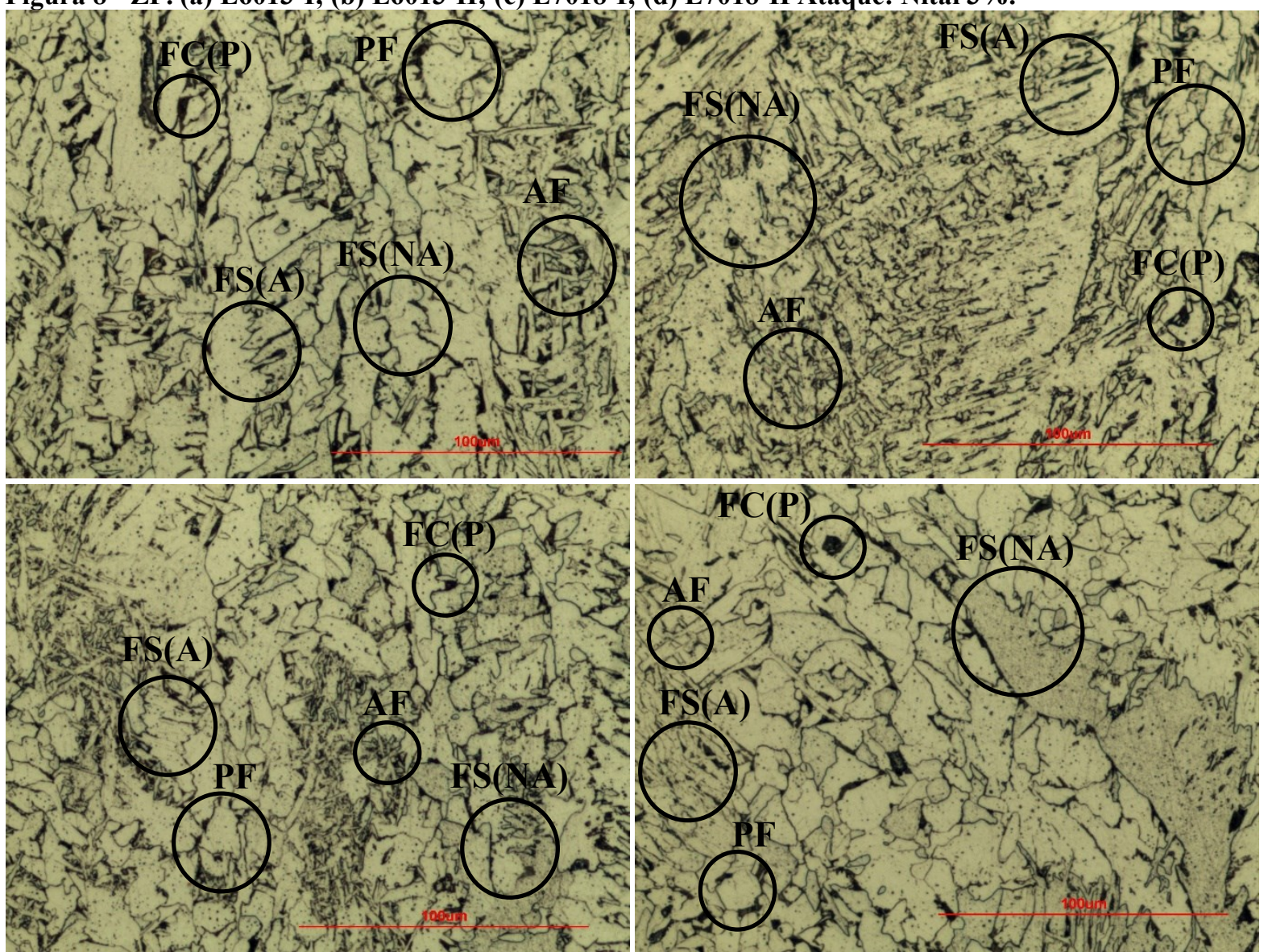

Fonte: Arquivo pessoal dos autores (2021)

As microestruturas das ZFs apresentaram os mesmos microconstituintes em todas as condições, entretanto nota-se que as amostras E6013-II e E7018-II, apresentaram estruturas mais grosseiras, quando comparadas com as amostras E6013-I e E7018-I, respectivamente.

\section{CONCLUSÃO}

Os consumíveis que foram armazenados conforme as especificações do fabricante, proporcionou uma solda com um melhor aspecto visual e contribuiu para uma melhor soldabilidade. Já os consumíveis que não seguiram as especificações, apresentaram maior dificuldade de soldagem, dificultando a abertura do arco de solda e resultando em um cordão de solda com aspecto de menor qualidade, além de alguns inconvenientes durante o processo como excesso de fumos metálicos e defeitos superficiais, identificados no ensaio visual.

Os ensaios de dureza não mostraram variações significativas entre as condições analisadas. As variações de dureza entre MB, ZTA e ZF ficaram dentro das especificações.

A metalografia apontou uma similaridade microestrutural nas amostras analisadas, evidenciando apenas estruturas mais grosseiras dos consumíveis não armazenados corretamente.

\section{REFERÊNCIAS}

ALVES, Sandra Mara de Souza. Características microestruturais e mecânicas de juntas soldadas em multipasses pelo processo GMAW de um aço API 5L X65Q. 73p. 
Dissertação (Mestrado em Engenharia de Materiais) - Univ. Federal de Ouro Preto, MG, 2016.

COLPAERT, Hubertus. METAlOGRAFIA dos Produtos Siderúrgicos Comuns. $4 .^{\circ}$ Ed, São Paulo: Edgard Blücher Ltda. 2008.

ESAB. Apostila de Eletrodos Revestidos. Disponível em: https://www.esab.com.br/br/pt/education/apostilas/upload/1901097rev1_apostilaeletrodosreve stidos_ok.pdf. Acesso em: 15 fev. 2021.

EUTETIC. Armazenagem de Eletrodos Revestidos. Disponível em: http://www.eutectic.com.br/catalogos/armazenagem_eletrodosrevestidos.pdf. Acesso em: 07 mar. 2021.

GARCIA, Amauri; SPIN, Jaime Alvares; SANTOS, Carlos Alexandre. Ensaio dos Materiais. 1. ed, Rio de Janeiro: LTC - Livros Técnicos e Científicos Editora S.A., 1999.

GUEDES, Ricardo Pereira. Influência da corrente de soldagem nas propriedades de juntas de aço de alta resistência e baixa liga soldadas com eletrodo revestido. 76p. 2009. Dissertação (Mestrado em Engenharia Mecânica). Univ. Federal de Pernambuco, PE, 2009.

INFOSOLDA. Condições gerais para armazenamento e secagem dos eletrodos. Disponível em: https://infosolda.com.br/wp-content/uploads/Downloads/Dicas/condiesgerais-para-armazenamento-e-secagem-dos-eletrodos.pdf. Acesso em: 23 fev. 2021.

IRIKURA, Sandra Ilka. Estudo da Influência da Microestrutura no Comportamento Mecânico de Juntas Soldadas de um Aço Estrutural. 171p. Unesp - Universidade Estadual Paulista. Dissertação (Mestrado em Engenharia Mecânica), Ilha Solteira-SP, 2006.

LIMA II, E. J.; BRACARENSE, A. Q. Soldagem robotizada com eletrodo revestido utilizando controle de comprimento do arco elétrico com compensação da temperatura do eletrodo. Tecnologia em Metalurgia e Materiais, São Paulo, v.4, n.2, p. 33-38, out. 2007.

LIMA JÚNIOR, Diniz Ramos de. Caracterização microestrutural e mecânica de juntas soldadas utilizando os processos GTAW, FCAW e SMAW. 81p. Dissertação (Mestrado em Engenharia Mecânica) - Universidade Federal de Pernambuco. PE, 2013.

MARQUES, Paulo Villani; MODONESI, Paulo José; BRACARENSE, Alexandre Queiroz. Soldagem Fundamentos e Tecnologia. 3. Ed, Belo Horizonte: UFMG, 2005.

MOTOYAMA, Valéria. Estudo da corrosão de aço ASTM A285 Grau C, utilizado em digestores de madeira com diferentes condições de soldagem. 123p. Dissertação (Mestrado em Ciência e Engenharia de Materiais). Univ. Estadual de Ponta Grossa, PR, 2007.

SANTOS, J. C. V.; DINIZ, A. A. A.; SOUZA, J. V. C.; SILVA, O. M. M.; RAYMUNDO, E. A.; SANTOS, C. E. F. Condições de Soldagem em Campo do Aço SAE 1045 pelo Processo de Eletrodo Revestido (SMAW). $21^{\circ}$ CBECIMAT - Congresso Brasileiro de Engenharia e Ciência dos Materiais 09 a 13 de novembro de 2014, Cuiabá, MT, Brasil.

WAINER, Emílio; BRANDI, Sérgio Duarte; Mello, Fábio Décourt Homem. Soldagem Processos e Metalurgia. 5. Ed, São Paulo: Edgard Blücher Ltda, 2005. 